\title{
The effects of verbal labels on the recognition of forms
}

RICHARD C. DEBOLO

WESLEYAN UNIVERSITY

Ninety-six Ss learned paired-associates with adjectives as stimuli and reproduced forms as responses. Tests for recognition of one form, a stressful rhombus, were made after $30 \mathrm{sec}$, or $48 \mathrm{hrs}$, or 7 days. The meaning of the stimulusword significantly influenced the PSE for recognition. There was no time effect.

Previous work (DeBold, 1963) on memory for form, using a reproduction test for memory has demonstrated an effect of the meaning of adjectival labels on the shape of reproduced forms. However, the reports of Ss at the time of the test for memory suggested alternatives to our interpretation of the results. $A$ number of $\mathrm{Ss}$ drew the forms from memory and then, when they examined their work, said that the reproduction was different from the forms they had learned. In most cases, the forms had, in fact, been distorted in a direction consonant with the meaning of the verbal label. Nevertheless, there appears a strong possibility that our results might be due to some aspects of the motor task during reproduction and not to the actual memory trace which the $\mathrm{S}$ might be able to use in order to recognize correctly the figure he had learned.

To test this possibility, we devised a recognition test for memory for form and replicated our previous work using this new test.

Method

Ss were 96 male undergraduates at Wesleyan University. Ss were paid to participate. Ss were assigned to conditions in rotation, one each, as they appeared for the experiment. All Ss completed the experiment.

As in the second experiment of the DeBold set (1963), the learning task consisted of a four-pair paired-associate procedure with adjectives for cues and forms as responses. The procedure during learning was exactly as in DeBold (1963). After a study trial, $S$ saw an adjective, drew the appropriate flgure from memory on a plece of ontonskdn paper, and then checked his anticipation by placing his drawing over the correct figure. There were nine anticipation trials. One change was made in the stimulus cards. The tilted rhombus was altered slightly to give a P.O.E. of $2.0 \mathrm{in}$ order to simplify the manufacture of the recognition stimuli.

For the recognition test, 15 additional cards were prepared as shown in Fig. 1.

The eighth card in the series is exactly the same as the standard used in the learning task. There were seven cards in each direction, which vary in the length of the shorter diagonal by a constant amount of $1.41 \mathrm{~mm}$, except that the last three cards in each direction have a difference twice as great, or $2.82 \mathrm{~mm}$. This unusual procedure was designed to give a series of stimuli in which the cards close to the point of objective equality were quite difficult to tell apart; that 1s, they were close to the difference threshold. In addition, the end cards were sufficiently far from the limens so as never to be missed. Finally, we wished to have as small a number of cards as possible in order to minimize subject fatigue during the recognition testing.

Recognition tests of memory were run after $30 \mathrm{sec}$, or $48 \mathrm{~h}$, or one week. The technique was a constant stimulus method. Each $S$ was presented with the serles of cards three times, each card singly. The cards were presented in three different random orders. The $\mathrm{Ss}$ were asked to judge whether each form was pointiler or less pointy than the flgure he had learned to draw. No labels were present during the recognition tests. A point of subjective equality was computed for each S, using the Urban-Culler Phi-process method for the diagonal ratio limen.

\section{Results and Discussion}

During the acquisition series, learning occurs, in the sense that the SB do not make anticipation errors in the paired-associate task. The four-pair task is well within their immediate memory span. However, when absolute errors in drawing of the rhombus are plotted over learning trials, there is only slight evidence of improvement in the accuracy of the drawings. The Ss copy well, show an immediate increase in

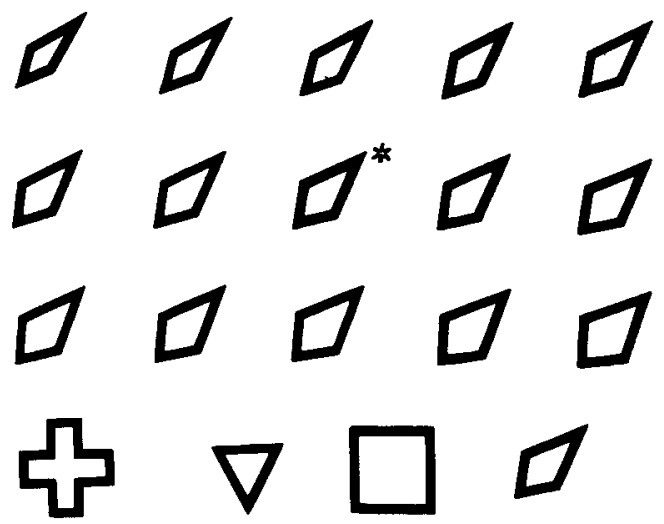

Fig. 1. The stimuli used in the learning task and in the recognition task. The bottom row of figures is that used in leaming. The starred figure is the standard. 


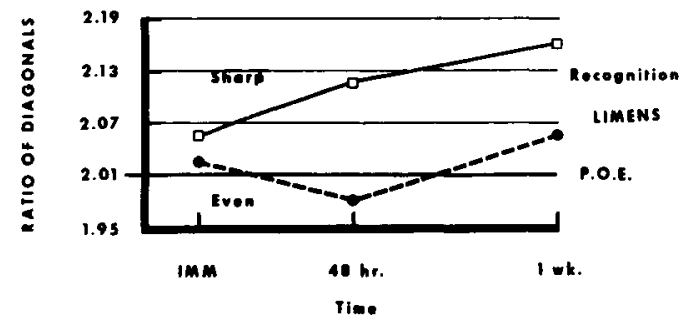

Fig. 2. The PSEs for the recognition task.

error on the first anticipation trial, and small but steady improvement which is not significant. An analysis of the label effect on the learning trials indicates no significant difference between label groups over all the learning trials ( $F=0.71, \mathrm{df}=1 / 94, \mathrm{~ns}$ ).

There is a highly significant effect of label on the recognition PSE. Groups who saw "sharp" during the learning trials judged a PSE pointier than that judged by the groups who saw "even" ( $F=6.91$, df $=1 / 90, p<.01$ ). As shown in Fig. 2, the group which saw "sharp" during learning shows a progressive increase in the pointiness of the PSE. The group which saw "even" was less sharp at $30 \mathrm{sec}$, became even less sharp at $48 \mathrm{~h}$, and sharpened at one week. The net effect was no significant difference over time ( $F=2.01, \mathrm{df}=2 / 90, \mathrm{~ns}$ ), and the interaction of label and time was not significant $(F<1.0)$. An analysis of the individual curves did not yield an effect over time.

The failure of the time effect to appear in recognition and the poor learning suggested further analyses of the data which corrected each S's PSE for the actual dimensions of the figure which he drew on the last learning trials. Two analyses were performed. The first compared the effects of labels correcting the PSE for the mean of the last two trials of learning, the second corrected for the last trial. We simply subtracted each S's recognition PSE from the average dimensions of the figures he drew on Trials 9 and 10 during learning in the first analysis and from the dimension of the figure he drew on Trial 10 in the second analysis. Neither analysis of variance resulted in a significant effect of label $(F=0.45$, df
$=1 / 90$, ns; $F=1.94$, df $=1 / 90, n s)$. This fact can be interpreted in two ways: First, it is possible that the effect of label is a perceptual effect, that is, a set. Groups which learn with a particular label tend to perceive the figures in a different way. Although this does not result in a significant difference in drawings during learning, when the effect is coupled with the recognition task, where the label probably acts as a mediator, the PSE differs highly significantly. Second, since we can predict $\mathrm{Ss}^{\prime}$ recognition PSE by examining their last drawings during learning, and since both groups have immediate access to the correct figure during learning, differences may be due to the effect of the habits associated to the label. These results imply that theories of progressive change in memory must consider the immediate effect of the label or other structuring events in the surround in influencing the set of the observer to perceive an object in a way consistent with the label. Our results also imply that reproduction and recognition tasks differ in the degree to which the elapse of time affects performance. We find it difficult to believe that there is a difference in "'memory" (as stored) between the Ss in the two conditions. Therefore, the method by which we measure memory may be an important factor in producing temporal effects. The evidence appears to favor an associationist position on memory change because of the role of motor habits in influencing reproduction (DeBold, 1963). But the "set" effects of the label would cause little difficulty for the Gestalt hypothesis since the recognition task does not yield significant effects over time. Associationists would explain the results in terms of the meaning of the label as a habit and the Gestalt hypothesis might suggest that the perceptual field is structured by the word and its effect on the perceiver.

\section{Reference}

DeBold, $R$. C. The influence of verbal labels on reproduced forms (1963). A paper presented at Western Psychological Association Meetings.

\section{Note}

1. E. J. Mayland provided technical help. 